\title{
$\underline{\text { A disaster diplomacy perspective of acute public health events }}$
}

Charlie Whittaker: School of Public Health, Imperial College London, Norfolk Place, London, W21PG. charles.whittaker16@imperial.ac.uk

Anna Frühauf: LSHTM Faculty of Public Health and Policy, 15-17 Tavistock Place, London, WC1H 9SH. ak.fruehauf@t-online.de

Samuel John Burthem: School of Public Policy, University College London, Gower Street, London, WC1E6BT samuel.burthem.16@ucl.ac.uk

Rebecca Shoshanah Parry: St George's, University of London Cranmer Terrace London SW17 0RE.m1200521@sgul.ac.uk

Meghana Kotikalapudi: Faculty of Medical Sciences The Medical School Newcastle University Framlington Place Newcastle upon Tyne NE2 4HH United Kingdom m.kotikalapudi@ncl.ac.uk

Yihui Liang: School of Public Health, Imperial College London, Norfolk Place London W2 1PG. yihui.liang16@ic.ac.uk

Mary Moffett Barker: Department of Health Sciences, University of York, Heslington, York, YO10 5DD mmb529@york.ac.uk

Parth Rohit Patel: University of Cambridge School of Clinical Medicine, Addenbrooke's Hospital, Hills Road, Cambridge, CB2 0SP editorinchief@ polygeia.com

Ilan Kelman: University College London and University of Agder, London UK and Kristiansand Norway, WC1E 6BT ilan_kelman@ hotmail.com

\begin{abstract}
Conceptions of acute public health events typically assume that they are tackled exclusively or principally through technical and medical solutions. Yet health and politics are inexorably linked. To better understand this link, this paper adopts a disaster diplomacy perspective for analysing and assessing the impacts of acute public health events on diplomatic outcomes. Two gaps in understanding disaster-health-politics connections are addressed: (i) how health interventions can impact diplomatic endeavours, especially for (ii) acute public health events. Three diverse case studies are interpreted from a disaster diplomacy perspective: Cuba's medical diplomacy, China and Severe Acute Respiratory Syndrome (SARS), and polio vaccination. Disaster diplomacy permits deeper investigation and analysis of connections amongst health, disaster, and diplomatic activities by viewing efforts on acute public health events as being political through disaster risk reduction (beforehand) and disaster response (during and afterwards). Understanding improves of how health interventions affect diplomacy and of disaster diplomacy's limitations.
\end{abstract}

\section{Introduction}

Politics and disasters are inexorably linked. Politics shape the underlying conditions and processes creating and perpetuating the vulnerabilities which are the fundamental causes of 
disasters. Vulnerability refers to the social processes placing people in harm's way without the choices, resources, or means to counter the challenges (Hewitt, 1983; Lewis, 1999; Wisner et al., 2004). Efforts to reduce vulnerability and to prevent disasters are focused on disaster risk reduction (DRR) which has meant tackling the causal factors of disasters by improving social conditions. These efforts are often presumed to be primarily technocratic which can bypass politics. Yet being related to processes such as resource distribution, social services, and governance, typically steeped in ideology, DRR and vulnerability reduction are inherently political (Drury and Olson, 1998; Olson and Drury, 1997; Olson and Gawronski, 2010; Siddiqi, 2014).

One approach investigating disaster-politics intersections is 'disaster diplomacy'. Disaster diplomacy seeks to understand how and why disaster-related activities, whether pre-disaster (DRR), post-disaster (rebuilding and associated activities), or during disasters, shape or do not shape diplomatic endeavours. Disaster-related activities include health-related disasters such as disease outbreaks and other acute public health events. Limited work has examined how health interventions can impact diplomatic endeavours, especially for acute public health events.

Motivated by this, this paper adopts a disaster diplomacy perspective to contribute to a better understanding of the way in which acute public health events influence diplomacy. In doing so, it seeks to better connect health-related and disaster-related activities through their potential influences on diplomacy. It also emphasises the reality of examining acute public health events, and activities to address them, as political endeavours rather than as being mainly medically related. The discussion thus moves analyses of acute public health events (conceptualised here as disasters) away from principally technical and medical considerations to encompass their complex socio-political context. In turn, this informs and expands our understanding of the political and diplomatic ramifications of both acute public health events and the medical responses to them. Doing so addresses theoretical and empirical gaps lying at the intersection of the fields of disaster studies and public health, and provides a further bridge between disaster-related and health-related work.

The next section provides an overview of the theoretical basis for disaster diplomacy, diplomacy, and acute public health events. Then, the following section applies the theory to establish the intimate connection between health/medical activities and politics/diplomacy. It expands the identified current research gap on this topic and details how disaster diplomacy might contribute to filling in the gap. To address this gap, the paper then analyses three diverse case studies of acute public health events using a disaster diplomacy approach to explore their impact on diplomatic activities. This analysis highlights how acute public health events have the capacity to affect positive and long-lasting changes to diplomacy provided that a preexisting basis is present from which those diplomatic activities can emerge. A synthesis and analysis section links the three case studies to explore the possible reasons underpinning these differences between acute public health events and prior disaster diplomacy work. Concluding remarks summarise this paper's contribution.

\section{Theoretical basis}

Disaster diplomacy has been applied to a wide range of hazards, vulnerabilities, disaster-related situations, and diplomatic situations including earthquakes and wildfires in Greece and Turkey (Koukis et al., 2016), the 2004 Indian Ocean tsunamis (Enia, 2008), and a hurricane affecting the USA (Kelman, 2007). One key conclusion emerging from this work is the importance of 
pre-existing factors in influencing the extent and magnitude of diplomatic outcomes occurring from disaster-related activities (Kelman, 2012, 2016; Lewis, 1999; Wisner et al., 2004). The overall disaster diplomacy conclusion from theory, case studies, and analyses so far is that disaster-related activities can sometimes catalyse short-term diplomacy due to a pre-existing basis, but disaster-related activities do not create new, long-term diplomatic endeavours (Kelman, 2012, 2016).

Part of the explanation for why these observations occur consistently emerges from the theorisation of diplomacy. Across many schools of thought (e.g. Bull, 1977; Nicolson, 1939), diplomacy is fundamentally peaceful negotiations for political matters. Traditionally, these negotiations have been theorised as taking place amongst sovereign states by official representatives of the states. In practice, and now accepted in theory (e.g. Duchacek et al., 1988; Diamond and McDonald, 1993), many parties other than sovereign states and their representatives are involved in diplomacy. Examples of such parties beyond politicians and diplomats are sports personalities, journalists, scientists, entertainment icons, business leaders. These diplomatic players extend to many different governance entities such as the United Nations, NATO, sub-national authorities (such as cities, provinces, and non-sovereign territories), corporations, media outlets, and research institutes.

Consequently, by definition, diplomacy has many forms, many parties, many reasons, and many drivers. Dealing with disasters - before, during, and after-is one such potential driver amongst many. With extensive knowledge regarding how neither the post-disaster imperative for response nor DRR are necessarily political priorities for any power regime (Devereux, 1993; de Waal, 2005; Hewitt, 1983; Lewis, 1999; Wisner et al., 2004), no immediate reason exists for why any disaster-related activities should necessarily be diplomatic priorities or influence diplomacy to a large extent. Nevertheless, theoretical reasons for why disaster diplomacy might not be expected to work need to be tested in practice with grounded case studies.

One class of case studies which disaster diplomacy research to date has not examined in depth is acute public health events and the related health activities, again covering pre-disaster, during disasters, and post-disaster. Whilst research has explored the impact of medical and health work on diplomatic relations between countries more broadly (e.g. Feinsilver, 2010ab; Thompson, 2005; Forster, 2015), less attention has been paid to the potential diplomatic impact of medical and health activities related to acute public health events. A disaster diplomacy perspective explicitly focuses on these links and thus is particularly useful to be tested to help determine its usefulness and applicability.

An acute public health event is defined as an event presenting an immediate threat to human health and hence requiring prompt action through control and mitigation measures to protect the health of the public (WHO, 2013). This definition includes events that have not yet led to disease in humans, but which have the potential to cause disease through exposing humans to infected or contaminated materials (WHO, 2013). Examples under this definition which are considered to be acute public health events are communicable disease outbreaks (including both actual outbreaks and potential ones, such as the threat of cholera due to a compromised water supply); populations experiencing famine and acute malnutrition; and large-scale incidences of injuries and fatalities. Acute health public health events (Figure 1) fit into discussions which seek to define a 'disaster' and analyse the characteristics of disaster (Furedi, 2007; Quarantelli, 1998; UNISDR, 2017). 


\section{All disasters}

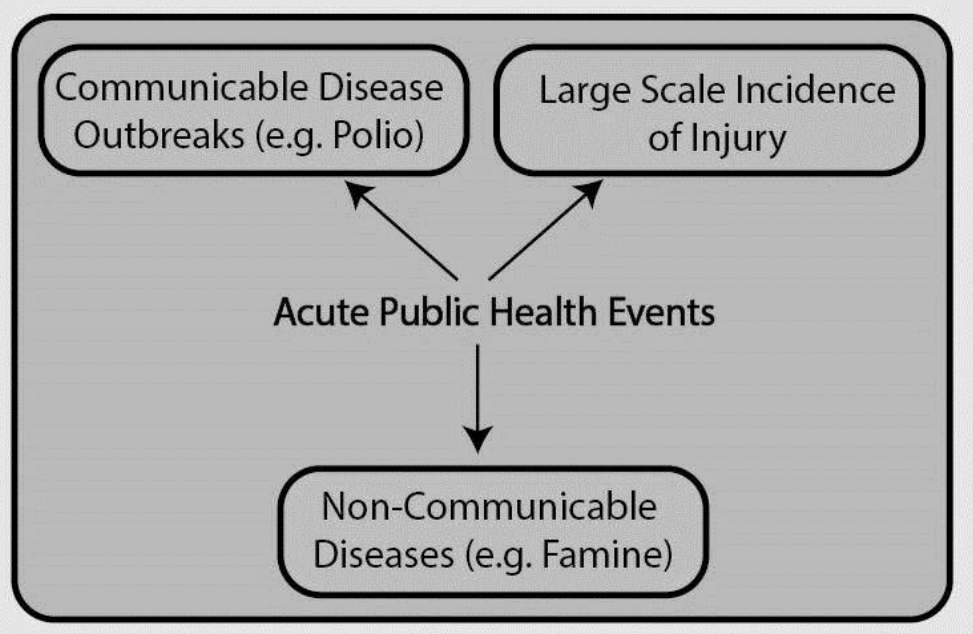

Though the above suggestions represent definitive examples, what constitutes an 'acute' event in theory is ultimately ambiguous and lacks clear demarcation. For this paper, the focus is on health or medical situations occurring on timeframes in the range of immediate to months (Figure 2). The recent famine in South Sudan and surrounding countries (Scribner, 2017) would represent an acute public health event under this definition. The reason is due to its nearterm impacts on the nutritional status of the population, as well as on health more broadly. A similar instance was observed during the 1984-1985 famine in Darfur where the majority of the deaths were attributed to the significant health crisis resulting from the famine, rather than the famine itself (de Waal, 2005). Meanwhile, instances of chronic malnourishment occurring over many years would not be an acute public health event. An example is the double burden of obesity and malnutrition in Benin with chronic and multiple causes (Manyanga et al., 2014). 
Figure 2: Timeline for defining acute public health events

Example of Disaster Timescale of Impacts

1- Cholera Outbreak

2- Famine (Causing

Acute Malnutrition)
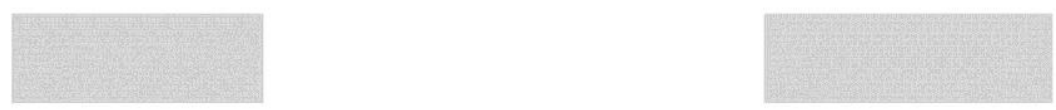

3- Chronic Malnutrition

Definitely an acute

medical crisis

Probably an acute medical crisis

Not an acute

Days Weeks Months

Years

Decades and medical crisis

Longer

\section{Health-Politics Interactions}

Although still somewhat contested in the current literature, this paper accepts that an inexorable link exists between politics and health. Examples are the way in which different political ideologies can shape health systems (Buşoi, 2010) and the role that politics plays in influencing the societal processes causing health outcomes (Murray et al., 2006). Such relationships are also observed at the individual level. Indeed, medical personnel frequently transcend political differences between their countries in pursuit of common health outcomes. An example is establishing the joint Israeli-Palestinian professional association, the Middle East Association for Managing Hearing Loss (Skinner et al., 2005).

Many authors examine the diverse, causal impacts of politics and political processes on health systems and outcomes. Examples include assessing the socio-economic basis of health inequalities across populations (Marmot, 2005; Navarro et al., 2006); the politics of public health policy (Oliver, 2006); and the World Health Organization's (WHO) highly influential framework on the Social Determinants of Health (WHO, 2010). Whilst the primary focus has therefore traditionally been on the ways in which politics and political processes shape health (e.g. Marmot, 2005), analyses of the impacts of medical and health work on politics such as diplomatic endeavours do exist in the literature, although to a lesser extent.

One notable example is Cuba's export of medical personnel to poorer countries to support healthcare infrastructure as a form of medical diplomacy (Feinsilver, 2010ab). This practice is now emulated across Africa by China (Thompson, 2005), as observed during the 2014 Ebola outbreak in West Africa (Huang, 2017), and by the US government's deployment of hospital ships around the world (Forster, 2015). The examples are not only contemporary. Pearson (2004) details how medical diplomacy by imperial powers in the early nineteenth century was employed to gain access to new markets for trade. American, British, and French authorities in North America would promise indigenous peoples inoculation from smallpox in return for exclusive and unmolested access to new hunting grounds for fur trappers. The expansion of hunting contributed to the continuing colonisation, extermination, and marginalisation of North American indigenous peoples. The indigenous peoples could not win. They would die from either smallpox or colonisation. 
Because such examples are scattered in the literature, a key gap remains within this field situating this medical diplomacy in the context of disasters, specifically acute public health events. The reason is perhaps a consequence of health practitioners' traditional views surrounding medical and health activities during acute public health events which would be considered to be scientific, technical, and apolitical (Katz, 2008)-mirroring some views of DRR and disaster response. Consequently, it is feasible that little work has been completed on medical diplomacy in disaster contexts because of a prevalent view that such work is not necessary or relevant. The small amount of literature exploring this theme suggests otherwise, indicating that much more work is needed. For instance, researchers are documenting community-level experiences of peace through health and arguing for the need for more such approaches while identifying remaining gaps and challenges (Arya, 2017). In fact, without fully understanding how acute public health events and related activities/responses might impact diplomacy — rather than the other way around of diplomacy being needed to deal fully with, for instance cross-border acute public health events - foreseeable negative consequences on health and conflict could arise.

In particular, neutrality, independence, and impartiality constitute the ideological foundation of many of the largest providers of post-disaster medical aid, such as Médecins Sans Frontières (MSF) and the International Committee of the Red Cross (Brauman, 2012). This stance is thought to facilitate access for these organisations to peoples and areas otherwise inaccessible for political reasons, allowing them to operate in active conflict zones (Bussmann and Schneider, 2016; Krähenbühl, 2004). The principles of neutrality, independence, and impartiality do provide a useful framework for operating, as demonstrated by the continuing work of the groups adopting the principles and their achievements without denying gaps and challenges (Anderson, 1999; La Rosa, 2006; Stoffels, 2004).

These principles have nonetheless proved to be difficult to maintain in many situations and have been heavily critiqued and contested throughout the literature, with many arguments highlighting the inability of disaster response activities to escape the political (Anderson, 1999; Cooley and Ron, 2002; Cuny, 1983; Duffield, 2001; Lischer, 2003). Medical interventions during violent conflicts are invariably affected by the political and social contexts in which they occur. The medical ethics of public health actors, including in disaster response, thus become difficult to maintain consistently with regards to neutrality, independence, and impartiality while ensuring positive impacts (e.g. Ahmad and Smith, 2018; Anderson, 1999; Cuny, 1983). Case studies and on-the-ground experience (Ahmad and Smith, 2018; Cooley and Ron, 2002; Duffield, 2001; Lischer, 2003) show how ignoring the politics-health connection in disaster response contexts can create unintended negative consequences. On occasion, it even prolongs or worsens conflicts and detrimentally affects the health of the population which the interventions were trying to improve.

One example was in 1995 during the Liberian civil war with the looting by local warlords of over 400 aid vehicles and millions of dollars of equipment which were then used for military purposes including purchasing weaponry (Okumu, 2003). The presumptions of neutrality, impartiality, and independence were not accepted by the looters, so the efforts to improve health ended up providing materiel for the conflict. Pottier (2006) argues that during the 19992004 Ituri conflict in the eastern part of the Democratic Republic of Congo (DRC), aid organisations had difficulty negotiating access to the two ethnic groups in conflict with each other because the majority of the aid workers were ethnically Congolese. The Congolese were associated with state oppression from Kinshasa by both ethnic groups in the conflict. Distrust 
of the humanitarian motivations eventually led to the majority of the NGOs pulling out. The efforts to deliver humanitarian assistance inflamed already existing ethnic tensions.

Aid provision to Rwandan refugee camps in then-Zaïre after the disaster of the 1994 Rwandan genocide has been well-documented as fuelling the abuse of power by the rebel leaders who controlled the camps (Terry, 2002). These warlords taxed humanitarian agencies, sold the received aid on the black market to further fund fighting, and used medical aid to treat soldiers injured in combat to return them to fighting. The premise here is that not intervening for postgenocide health work would have helped the population's health outcomes more than the attempted interventions. Some groups agreed, with MSF-France and Care-Canada eventually withdrawing from some of the Rwandan refugee camps. Some groups disagreed, with MSFBelgium and MSF-Holland remaining in the camps.

There are also incidences of medical missions expanding their remit to respond to specific needs on the ground. Dijkzeul (2003) discusses how the collapse of state welfare provision in eastern DRC had significant effects on the way in which health NGOs implemented their programmes. They were essentially required to step into a role previously run by the state which meant administrating healthcare and the attendant social welfare programmes supporting healthcare provision. The medical programmes in eastern DRC relied on locals paying for services, so the NGOs were forced to ration services for those who could not pay. Dijkzeul (2003) shows that the goals of medical NGOs in contexts such as eastern DRC are affected by the realities and contexts of the local situation.

The conclusion is that, operationally, health interventions are not divorced from politics and that aid interventions do not always yield positive health outcomes, no matter what the intentions. Despite the exploration of this theme in the literature by academics and practitioners (e.g. Ahmad and Smith, 2018; Shawcross, 2000; Terry, 2002), some authors still advocate for the unconditional use of vaccine diplomacy and other medical diplomacy interventions to advance foreign policy and to bring countries together (Hotez, 2014).

The above examples illustrate that health interventions, including during acute public health events, have widespread political consequences and hence have the potential to affect diplomacy. Not admitting the wider political and diplomatic ramifications of health interventions in disaster contexts might lead to unintended negative consequences. It could also constrain and limit the scope of leveraging medical and health-related activities to achieve longer-lasting positive ends, from both political and health perspectives. Such potentially positive outcomes are nonetheless continually sought and expected, perhaps in naïve optimism or perhaps with a design to ensure that success could be achieved. An example is the 'Days of Tranquillity' (temporary ceasefires) programme established in Sri Lanka between warring factions in order to immunise children (Keating and Knight, 2006). The immunisation succeeded, but the conflict continued. This phenomenon of ceasefires being respected for child vaccination programmes followed by a resumption of hostilities has been repeatedly observed in many other locations, including Afghanistan and Sudan (Arie, 2013).

A wide array of potential diplomatic impacts and lack of impacts therefore arises from medical and health activities occurring around and in response to acute public health events. Yet the current literature on the topic is sparse compared to the academic body examining other instances of politics-health connections. A disaster diplomacy perspective assists in framing this topic in such a way that diplomatic impacts, or lack thereof, from dealing with acute public 
health events are clearly seen. A deeper investigation and analysis emerges of connections amongst health, disaster, and diplomatic activities.

Consequently, the rest of this paper contributes to filling this research gap, through case studies and analyses to support the existing calls in the literature. This material helps to explore this topic more deeply for determining whether or not greater efforts should be put into using health interventions to influence diplomacy.

\section{Case study 1: Cuba's Medical Diplomacy}

From a small medical team sent to Chile following an earthquake in 1960 to almost 60,000 medical professionals currently operating in over 90 countries around the world (Huish and Kirk, 2007; Waller et al., 2017), the extent and scale of Cuba's overseas medical assistance is renowned and respected by the recipients. This medical aid has had varying diplomatic benefits (Feinsilver, 2010ab), as demonstrated by the differing results of Cuban medical diplomacy for acute public health events in Venezuela and the US, both of which will be discussed here.

\section{Historical overview}

Cuba's recent medical work in Venezuela began in 1999, initiated by the rise of Hugo Chavez, who in comparison to his predecessor, was personally known to Fidel Castro and followed ideologically aligned (though not identical) policies. The first intervention was a disaster response programme, with the deployment of doctors to Vargas State in Venezuela following the 15 December 1999 acute public health event of mudslides killing between 10,000 and 30,000 people, later known as 'Vargas Tragedy' (Bergamaschi et al., 2017). The tragedy highlighted the inability of an ailing Venezuelan healthcare system (Briggs and MantiniBriggs, 2009) to deal adequately with acute public health events and it established Cuba as a pivotal player in mitigating the consequences.

The following year saw the signing of the 'Integral Cooperation Agreement' between the two countries. This agreement involved the exchange of goods, primarily oil from Venezuela, for services from Cuba, typically medical. Also known as the 'oil for doctors' agreement, it stipulated preferential pricing on Cuba's export of medical services in return for a reliable supply of Venezuelan oil, amongst other exchanges (Feinsilver, 2008). It formalised the medical diplomacy that Cuba had previously been operating and strengthened ties between the two countries, thus making the agreement more than just an exchange of goods and services.

Relations between the countries via this agreement became more entrenched over the coming years. Cuban medical services proved to be integral to the operation of Plan Barrio Adentro ('Inside the Neighbourhood Plan'), an ambitious programme designed to improve health care access amongst some of the most impoverished and underserved communities in Venezuela. Staffed extensively by Cuban medics, the initial programme was born in the Libertador Municipality. Here, memory of Cuban medical activity during the Vargas Tragedy led officials to initiate discussions with the Cuban Embassy that produced an agreement bringing a group of Cuban physicians to Libertador (Briggs and Mantini-Briggs, 2009). This plan would eventually be rolled out nationwide under the auspices of 'Misión Barrio Adentro'. A second agreement was signed between Cuba and Venezuela in 2005, which saw Venezuela agree to provide 53,000 barrels of petroleum daily in return for further expansion of the medical services Cuba provided (Yánez, 2005). Based on pre-existing ideological similarities, extensive ties between the two countries emerged from Cuba's medical diplomacy, starting 
with the response to the 1999 Vargas Tragedy and becoming a cornerstone of VenezuelanCuban relations.

In contrast to this comparative success, the results of Cuba's medical diplomacy efforts with the US have failed. Following the Hurricane Katrina disaster striking the US, Cuba's offer of over 1,500 medical personnel, along with a substantial volume of medical supplies, was rejected by the US Government (Kelman, 2007). It has also been suggested that the US government's own medical ship missions were initiated as a medical diplomacy strategy in direct competition with Cuba, aimed at countering the spread of Cuban medical influence and reliance on Cuban medical personnel (Feldbaum and Michaud, 2010).

\section{Altered Attitudes?}

Medical diplomacy allowed Cuba to establish itself as the purveyor of medical aid in Venezuela's time of need during an acute public health event, aiming to support an ideological ally. Proffering medical support also gave Cuba leverage and bargaining power with which to negotiate steady petroleum supplies following the collapse of the USSR, whose provision of oil below world market prices had accounted for an estimated $90 \%$ of Cuba's energy needs at its peak (Pérez, 2014). Cuba's medical diplomacy therefore served multiple purposes of supporting a friend's health-related needs, strengthening diplomatic ties with that friend, and returning to Cuba needed goods. Rather than altering Venezuela-Cuba relations, the medical diplomacy firmed up what both leaders wanted already and helped to push forward already desired close connections.

Similarly, US-Cuba relations were not altered from their hostile state by medical diplomacy during the acute public health event of Hurricane Katrina. Instead, inertia pushed forward the animosity between the two countries.

These divergent outcomes from Cuba's medical diplomacy suggest the importance of preexisting alignment of political ideology for medical diplomacy to succeed. Whilst medical diplomacy can improve relations and move beyond acute public health events, as is evident from Venezuela, a pre-existing basis is needed which, in this case, was similar politics. Without this baseline, as with the US, medical diplomacy fails. When faced with already negative relations and ideological incongruence, disaster diplomacy ability's to be impactful and lasting appears to be limited, corroborated by the experience of Cuban medical diplomacy in the USA. While medical diplomacy might itself be a laudable goal without desiring wider outcomes, this case study has demonstrated that no assumptions can be made that medical diplomacy could necessarily expand beyond addressing only health needs.

\section{Case study 2: China, SARS, and WHO}

The 2002-2003 Severe Acute Respiratory Syndrome (SARS) outbreak started in China and spread globally. First identified in November 2002, the virus spread quickly from Asia to North America, Europe, Africa, and Oceania, before being contained in July 2003 (Lee and McKibbin, 2004; Chan et al., 2010), with 8,096 total cases and 774 dead (WHO, 2003). This case study focuses on the ways in which medical responses and processes related to the SARS outbreak shaped diplomatic outcomes for China with respect to WHO before, during, and after the SARS crisis. The example represents a perspective of disease diplomacy (as a subset of disaster diplomacy, with the outbreak being the disaster). It indicates how the acute public health event (the disaster) and the activities in response to SARS (the diplomacy) facilitated 
changes in how China diplomatically engages with international organisations and other countries.

\section{Historical Overview}

The initial Chinese response to the SARS outbreak was characterised by cases of mismanagement, inefficiency, and a lack of transparency, both domestically and internationally (Huang, 2004; Ahmad et al., 2009). There were delays in knowledge sharing across governmental hierarchies due to fear of repercussions stemming from delivering bad news (Huang, 2004; Ahmad et al., 2009). It occurred in tandem with an active cover-up in which the government used its control over the media to disseminate the message that there was no concerning disease threat (Huang, 2004). Despite continued reporting of cases within the healthcare network, wider information dissemination was restricted. An information blackout was enforced under strict government orders stating that public sharing of information about the disease would result in prosecution for leaking state secrets (Fidler, 2004; Huang, 2004; Hui and Ng, 2007; Ahmad et al., 2009).

The Chinese government's response was therefore initially grounded in secrecy and opaqueness, characterised by activities directly violating WHO regulations (Lee and McKibbin, 2004). China also obstructed the entry of WHO assessment teams arriving in the country to investigate the source of the virus (Chan, 2011), as well as limiting access to information on infection tallies from provinces. Indeed, the first report on the initial outbreak in Guandong province provided by China to WHO did not occur until 17 March 2003, five months after the first reported case in the region. All of this matches what was then the prevailing Chinese attitude towards supranational organisations like WHO, which was marked by passivity and a lack of engagement (Chan et al., 2010).

Failure to contain SARS in China coupled with the disease's spread outwards to other countries initiated more interest from WHO, alongside a major change in Chinese responses and attitudes towards both the outbreak and its relations with the organisation. A substantial shift in government action was witnessed, which manifested as the implementation of corrective measures in control and regulation; transparency regarding deaths and infected cases; and more open and up-to-date international communication. The Chinese government rapidly put in place several policies, including orders containing details of managing SARS in rural hospitals (Liu et al., 2014; Huang, 2004). Temperature checkpoints were established along intercity transportation points (Ahmad et al., 2009). To deter travel, major international events were cancelled along with a one-week May Day national holiday. The government also funded free SARS treatment to all infected cases (Huang, 2004; Ahmad et al., 2009). This change in the response to the disease was perhaps most notably seen in the announcement by Premier Wen Jiabao on 19 April 2003 stating that there would be severe consequences for those not reporting SARS cases in a timely and accurate manner.

These developments represent a significant shift in the way the Chinese authorities responded to the outbreak, a shift that saw movement from an opaque and denial-based approach to one characterised more by transparency and openness. Such a change in the Chinese government's approach to the outbreak is similarly reflected in their attitudes towards WHO. The government provided proactive and direct support following the arrival of a WHO team in Guangdong on 3 April 2003, with all requests for access to sites and interviews with health staff being readily granted (WHO, 2015). On a wider level, the outbreak inspired the establishment of new healthcare frameworks, with a new National Health Reform introduced containing new policy 
standards which aligned with WHO regulatory standards (Fidler, 2004; Lee and McKibbin, 2004; Chan et al., 2010). Change in leadership also saw new openness with foreign media and WHO on outbreak status, resulting in the release of figures which had previously been concealed and/or deliberately underestimated.

\section{Altered Attitudes?}

These altered attitudes continued long after the containment of SARS by the end of 2003. Following the crisis, Beijing became far more proactive in participating in global health governance, something that has been attributed to the SARS outbreak's demonstration of WHO's power and political importance (Chan et al., 2010). The change was illustrated by the engaged response of the Chinese government to isolated SARS cases in China in 2004.

Were these developments entirely new? China had had increasing prior engagement with global health, evidenced by Beijing's hosting of the Fourth World Conference on Women in 1995 with a health component (Forrest, 1995) and the Tenth World Conference on Tobacco or Health in 1997 (Lu et al., 2012). The period following SARS was characterised by greater active participation and leadership in international fora. These included China's hosting of a joint International Pledging Conference on Avian and Human Pandemic Influenza with the European Commission and the World Bank (WB) in Beijing in 2006. At this event, China helped to establish ground rules for health governance and global stewardship of health activities. China had also signed the WHO Framework Convention on Tobacco Control Treaty in November 2003, despite being the largest consumer and producer of tobacco worldwide. Chinese Vice-Minister of Health Huang Jiefu attended the conference on Cross-Strait Cooperation in Preventing H1N1 in 2010, an event emphasising cross-border collaboration in public health and information sharing.

Similarly, since the SARS outbreak, active political support from China witnessed a ChineseCanadian, Margaret Chan, twice elected as WHO's Director-General. Previously reported discussions with health officials in Beijing revealed China's support for the candidate to be a direct product of the country's realisation of the value and importance of WHO on the world stage (Chan et al., 2010), a view seemingly supported by the SARS crisis. China's financial position within WHO has also seen a dramatic reversal, with the country gradually going from being an equal recipient and contributor of approximately US\$5 million in 2005, to a net donor with China's contribution to WHO reaching US\$30 million in 2012 (Liu et al., 2014).

Due to the health system and political crises caused by SARS, and the disease's global nature, China was pushed to engage in much more open responses. The country adopted a revised foreign affairs approach of collaboration and leadership with respect to acute public health events. One result is significant improvements to China's ability to detect and respond to outbreaks. The Chinese response to the 2013 H7N9 Influenza flu outbreak is a testament to China's changed operations in cooperation for acute public health events, providing direct reporting to WHO in half the time taken for the SARS outbreak (Wang, 2013). These changes occurred within wider contexts (pre- and post-SARS) of China engaging more with multilateral organisations, such as a November 2002 agreement signed with ASEAN to improve regional collaboration regarding security threats.

The SARS outbreak nonetheless brought significant changes to the way in which China approached both public health and the supranational organisations responsible for the stewardship of public health activities, namely WHO. It shifted diplomacy revolving around 
China's recognition of the worth of international collaboration with regards to health, as well as appreciation for health activity as a vehicle for economic and political leadership. These changes have, thus far, lasted and are manifest in China's present-day approach to international health crises, such as the 2014 Ebola outbreak in West Africa (Huang, 2017). For China, the SARS outbreak was a turning point for its foreign affairs with political implications which continue to be seen today.

This case study emphasises the potential for disaster diplomacy to catalyse longer-term diplomatic impacts, provided that a pre-existing basis exists for this catalysis. Based on the acute public health event of SARS, it provides an improved understanding of how health interventions can impact diplomacy. It extends traditional disaster diplomacy research by considering the long-term impacts on diplomatic relationships, based on pre-existing conditions, resulting from activities surrounding an acute public health event as a disaster.

\section{Case study 3: Polio eradication}

The polio vaccine has vastly reduced the disease's incidence, with an increasingly limited number of regions being severely affected including areas of Nigeria, Pakistan, and Afghanistan. In this case study, work surrounding both polio outbreaks (disasters) and vaccine use (DRR) is explored across a diverse range of settings, to examine how different activities, all relating to the same disease (polio) and goal (eradication) can have differing political ramifications.

\section{Historical Overview}

The development of the live polio vaccine (1956-1959) has its roots in cooperation between the USA and the Soviet Union during the height of the Cold War (Hotez, 2014; Hotez et al., 2017). Political differences were set aside due to the fear of acute public health events through a major polio outbreak on top of the continuing, chronic incidences (Hotez, 2001). The vaccine's development and testing relied largely on the efforts of individual scientists in both countries convincing their diplomatic liaisons to put aside ideologies for purposes of joint scientific cooperation for preventing such outbreaks (Swanson, 2012; Hotez, 2014). Despite this cooperation between the two countries for avoiding an acute public health event, this working relationship did not have substantial effects on other areas of American-Soviet collaboration (Steinbruner, 1997).

Against this background, 1988 is often considered to be a milestone in the history of combatting polio. Efforts moved beyond bilateralism and took on a more global scope through the foundation of the Global Polio Eradication Initiative (GPEI) aimed at eradicating polio worldwide. This was made possible through collaboration with national governments, WHO, Rotary International, the US Centers for Disease Control and Prevention (CDC), and UNICEF (Baicus, 2012).

Although global eradication has yet to be achieved, progress has been made, especially considering opposition to it, such as the 2003 polio vaccine boycott in Northern Nigeria. Here, a boycott initiated by local governments led to acute public health events as disasters through polio outbreaks. Countries across Africa, the Middle East, and Southeast Asia were affected, with the origin in Nigeria and thus threatening to compromise many Nigerian Muslims' ability to make The Hajj to Saudi Arabia (Kaufmann and Feldbaum, 2009). The ban on the vaccination programmes resulted from rumours about the vaccine allegedly containing HIV, cancerous 
agents, and antifertility drugs said to sterilise young Muslim girls. These stories occurred against the background of post-9/11 western military interventions in predominantly Muslim countries and a meningitis antibiotic trial in Nigeria in which several children died (Jegede, 2007). The polio vaccine boycott led to costs of more than US\$500 million to control the polio outbreaks over the following years and ended hopes of eradicating polio in that decade (Kaufmann and Feldbaum, 2009).

The boycott was resolved through diplomatic actions taken by the GPEI and the UN focusing on having influential individuals in Nigeria, including the prominent Islamic scholar Sheikh Yusuf Al-Qaradawi, publicly acknowledge the safety of the polio vaccinations (Kaufmann and Feldbaum, 2009; Jegede, 2007). Ghinai et al. (2013) explain how the GPEI successfully engaged with the Sultan of Sokoto (the highest ranking leader in northern Nigeria) to declare publicly that the vaccines are safe. With added pressure from political allies and religious authority figures, the Nigerian polio vaccine boycott ended.

\section{Altered Attitudes?}

Despite the successes of the polio vaccination campaign in terms of tackling outbreaks against the background of disease eradication efforts, the relationships amongst parties in conflict dealing with polio did not improve on the basis of medical diplomacy. Both these polio-related acute public health emergency cases, the US-USSR one covering outbreak prevention (disaster risk reduction) and the Nigeria one covering outbreak response (disaster response), highlight the power of individuals to influence medical diplomacy on the health side but not on the diplomacy side, just as with disaster diplomacy. For Nigeria, the UN strategically decided to employ a Nigerian native with a significant family history in the country to help resolve the conflict between the Northern groups and the government to permit vaccinations. Explained by Ghinai et al. (2013), the UN recognised the need to target influential people in the community and to engage in cultural and social outreach. This feature stands in contrast to the US-USSR example, where the political climate between the two adversaries meant that the vaccine cooperation efforts undertaken were not widely publicised and were undertaken with governments on the lookout for espionage by the other side (Swanson, 2012).

Regarding US-USSR relations during the Cold War, there were always continuing bases for potential conflict resolution, which led to numerous agreements such as the Strategic Arms Limitations Talks/Treaties in the late 1960s and 1970s. Resolution of the fundamental ideological conflict did not occur until the USSR disintegrated in 1991. The re-emergence of Russia as a power has led to new Russia-US tensions a generation later. Effectively, providing a deeper understanding of the limitations of disaster diplomacy, polio vaccination and eradication attempts have had no fundamental influence on old and new Cold War politics, irrespective of the successes in vaccination. Fear of polio outbreaks led to scientific and medical collaboration for the diplomacy required for vaccinations (Hotez et al., 2017) and to substantial strides in averting continual polio-based acute public health events, but not for steps forward in wider US-USSR diplomacy. In fact, lack of diplomacy almost scuttled efforts to test the Sabin vaccine in the USSR in the 1950s due to mistrust. Suspicions were overcome by focusing on medical results only, rather than alluding to any wider collaboration between the two countries (Swanson, 2012). That is, success resulted by separating the vaccinations from wider politics as much as feasible.

The more recent example of Nigeria shows how lack of diplomacy can lead to an acute public health event. When the polio outbreaks spread, they motivated religious groups and countries 
such as Saudi Arabia to take action to help resolve the situation. In a display of short-term diplomacy, the fact that Saudi Arabia was openly considering making polio vaccination mandatory for Nigerians travelling to the country as part of The Hajj helped to undercut the contention that polio immunisation was a Western plot against Muslims (Kaufmann and Feldbaum, 2009). Religious and political ideologies inside and outside of Nigeria were set aside to combat the rumours surrounding the vaccination campaign, which could have been disaster diplomacy - except that the reconciliation turned out to be only temporary for the Nigerian conflict. With little pre-existing basis for ending the violence, the vaccinations continued, as did the conflict, and both continue today in Nigeria (Kew, 2016; WHO, 2017ab). This result is typical of disaster diplomacy in that short-term diplomatic gains can sometimes be seen, but do usually produce long-term diplomatic results (Kelman, 2012, 2016).

For Nigeria, the start and end of the polio vaccine boycott did not affect often violent cultural, religious, and social tensions throughout the country (Kew, 2016). Furthermore, where acute public health events in terms of polio outbreaks did occur due to the vaccine boycott - such as Côte d'Ivoire, Indonesia, Saudi Arabia, and Yemen - they were brought under control, but no influence was seen on conflicts in these countries.

Bringing the two examples together, although political and religious differences were set aside in the short-term to tackle acute public health events for the Cold War and for Nigeria, neither translated into new or improved diplomacy in the long-term. Using a new case study of dealing with acute public health events, these findings align with previous conclusions from disaster diplomacy (Kelman, 2012, 2016), which suggest that efforts surrounding disaster-related activities tend not to create new diplomatic relations. They can sometimes catalyse improvements in contexts where a pre-existing basis for the diplomacy exists. This case study thus provides an improved understanding of health-politics interactions for acute public health events, indicating the useful insights gleaned from a case study which did not yield much disaster diplomacy.

\section{Synthesis and analysis}

These case studies illustrate the capacity for acute public health events to achieve diplomatic impacts that are positive and long-lasting. They also indicate that the extent of such impacts can be highly varied and, fundamentally, depends on pre-existing factors. For Cuba's medical diplomacy with Venezuela, alignment of political ideology provided the pre-existing conditions permitting medical activities in response to acute public health events to elicit positive changes to diplomatic relations. Cuba-US medical diplomacy did not function due to a lack of pre-existing conditions. SARS appeared to elicit significant long-lasting changes to China's interaction with WHO, but was also based on pre-existing conditions. Preventing and responding to polio outbreaks led to collaboration amongst parties in conflict, but without wider impacts or consequences due to a lack of pre-existing conditions.

Hence, many conclusions here accord with those demonstrated elsewhere within the disaster diplomacy literature (Enia, 2008; Kelman, 2012, 2016; Koukis et al., 2016). This prior work has consistently observed that, whilst disaster-related activities often have the capacity to catalyse short-term diplomacy, this does not translate into new, longer, more profound shifts in diplomatic relations between the involved parties unless a pre-existing basis exists for the diplomacy. Similar observations emerge for acute public health events based on the case studies here. Thus, the legitimacy of disaster diplomacy's approach is supported while adding a novel public health dimension to disaster diplomacy and to the literature on the politics- 
disaster interface. Further originality emerges through demonstrating the usefulness of a disaster diplomacy perspective in highlighting the potential influence of health interventions on diplomacy. Corroborating previous work while pushing forward an original contribution demonstrates the usefulness and usability of viewing acute public health events as disasters and dealing with them as DRR. It provides insights for both health research and disaster research from diverse case studies.

Whereas the Cuba-Venezuela and Cuba-USA case studies are bilateral, China with SARS and polio vaccination raise questions about disaster diplomacy in the context of regional and global governance structures dealing with acute public health events. Examples of supranational bodies representing multilateral, non-governmental, and private sector organisations and institutions are WHO, the European Commission's Directorate General for Health and Food Safety, MSF, and pharmaceutical companies. A debate emerges (e.g. Buhmann, 2005) around the long-term capability of these players to generate significant, positive outcomes beyond public health; that is, achieving spillover from medical diplomacy to other diplomatic realms.

Should these players attempt to create new diplomacy from initiatives to deal with acute public health events, both through DRR and disaster response? Or should they should focus on providing health interventions rather than involving themselves in wider diplomatic activities, which must mean being highly political? Aspects emerging from the analysis here include considerations regarding infectious diseases, DRR for disease outbreaks, and increasing international collaboration. The three case studies in this paper provide a helpful baseline for expanding the remit of a disaster diplomacy perspective of acute public health events.

Consider further the current focus placed on moving authoritative decision-making and reporting procedures to the international level. This is evident in debates surrounding the International Health Regulations (IHRs) and the increasing ubiquity of aiming for international responses which are more centrally coordinated, whose inception depends on a declaration made by WHO's Director General (Gostin et al., 2015; Maini et al., 2017). WHO has developed into one of the most powerful agencies within the UN, keeping in mind that few UN agencies have extensive power, but WHO remains the only agency whose directives cannot be blocked by a Security Council member veto (Chan, 2010). This gives WHO, and notably individual states dominant within the agency (mainly through being donors), significant power to force, cajole, or encourage policy changes (Chan, 2010), as was seen during WHO's interaction with China regarding SARS.

As with WHO's uniqueness, could there be unique features of acute public health events which might differentiate them from other disasters, yielding a capacity to effect positive long-term diplomatic changes? Positive changes, based on the pre-existing conditions identified, were seen for Cuba-Venezuela and post-SARS China. One feature of acute public health events applying to post-SARS China, although not to Cuba-Venezuela, might be the established existence of a structural framework of international relations for which an operational and coordinating supranational organisation exists, namely WHO. WHO has a legally binding instrument of international law with the explicit aim of preventing, protecting against, and controlling the spread of disease, namely the IHRs. This feature of UN-based health diplomacy does not exist in similar forms for disaster-related activities.

The UN DRR focal point is the UN Office for Disaster Risk Reduction (ISDR). It is rarely operational in the sense of organising and implementing DRR projects on the ground and it does not seek a legally binding DRR instrument. Similarly, the mandate of UN Office for the 
Coordination of Humanitarian Affairs (OCHA) is exactly in its title: to coordinate humanitarian actions and responses. As with ISDR, it sits within the UN Secretariat and lacks significant legal powers. Hence, Cuba's post-disaster medical diplomacy is bilateral, rather than drawing on UN frameworks or institutions. Other UN bodies address specific topics within DRR and disaster response. Climate change is a significant hazard driver and climate change sits as a subset of DRR, yet these topics are separated from ISDR and OCHA. They are placed with the UN Framework Convention on Climate Change (UNFCCC) which runs international negotiations seeking legal agreements to deal with climate change. The UN Refugee Agency (UNHCR) takes responsibility for refugees and forced migrants, which can cover people displaced by conflict or other disasters.

Irrespective of the power, or lack thereof, of WHO or the other supranational bodies, the global public health sphere is characterised by a diversity of actors, including within the UN system. WHO's effectiveness is also challenged in many ways (Gostin, 2015). Nonetheless, the degree of fragmentation of actors, authority, legitimacy, legality, and documents is far greater for DRR and disaster response. The power of DRR and disaster response institutions for developing and enforcing legally binding regulations is also less than WHO's power. These differences might support the increased effectiveness of disaster diplomacy for acute public health events compared to activities for other forms of disaster.

Another factor could be that acute public health events and associated activities might represent higher priority issues for national governments than other disasters. Communicable diseases jump continents via air travel and can affect global business, as seen with SARS and Ebola.

Conversely, previous disaster diplomacy analyses have consistently demonstrated that disasterrelated activities are generally not a high political priority, especially when it comes to longterm commitments and actions. Interest in disasters and DRR impacting diplomacy has tended to be short-term and highly dependent on popular mobilisation and media coverage. Such work is often viewed as being mainly technocratic and apolitical, exactly as with health interventions. This occurs even though the vulnerabilities which cause disasters accrue over a long time period making disasters a long-term and highly political process, as is DRR (Hewitt, 1983; Lewis, 1999; Wisner et al., 2004). Yet global interest has been generated by acute public health events leading to wide-ranging, long-term political support for global initiatives such as the IHRs and disease eradication. Consequently, public health events might have potential to garner interest around wider DRR, especially admitting the political causes of and solutions to disasters including acute public health events, which could portend well for successful disaster diplomacy in the future.

\section{Conclusions}

This paper has identified, and contributes to filling in, two linked gaps in disaster-healthpolitics connections: (i) how health interventions impact diplomatic endeavours, especially for (ii) acute public health events, assisted by conceptualising them as disasters. Plenty of scope remains for further work and expanding the analysis here. Public health issues, as with DRR activities, operate over a range of time scales (Figure 2). Some are acute, as per this paper's scope. Others, such as chronic malnutrition, occur over longer timeframes and represent another conceptual challenge for analysis, especially examining more the delineation of time scales between short-term and long-term. Many public health challenges incorporate both acute and chronic aspects, such as famine and associated acute malnutrition increasing the risk of elevated cholesterol and various non-communicable, chronic diseases (Wang et al., 2017). 
Further exploration would be useful of the factors which might differentiate acute public health events from other types of disasters, especially to determine whether or not these factors might provide leverage to support health-related DRR and beyond. The importance of case studies which do not yield positive disaster diplomacy results is also affirmed.

The analyses here highlight the importance and limitations of exploring disaster diplomacy for public health and for other long-term actions. By examining acute public health events as disasters, public health and disaster-related work can also be brought more closely together. Such work would help to indicate the political implications of each and how to better extract positive diplomatic outcomes from the work - or to accept the futility of trying to do so. Thus, the fields would learn from each other, providing support to improve actions in both fields especially in the realm of diplomatic outcomes.

\section{References}

Ahmad, A., R. Krumkamp, and R. Reintjes (2009) 'Controlling SARS: A review on China's response compared with other SARS-affected countries'. Tropical Medicine and International Health. 14(1). pp. 36-45.

Ahmad, A. and J. Smith. 2018. Humanitarian Ethics and Action. Zed Books, London.

Anderson, M.B. (1999) Do No Harm: How Aid can Support Peace-or War. London: Lynne Rienner Publishers.

Arie, S. (2013) 'Polio outbreak leads to calls for a "vaccination ceasefire" in Syria'. BMJ. 347(f6682), https://doi.org/10.1136/bmj.f6682

Arya, N. (2017) 'Peace and health: bridging the north-south divide'. Medicine, Conflict and Survival. 33(2). pp. 87-91.

Baicus, A. (2012) 'History of polio vaccination'. World Journal of Virology. 1.4. p. 108.

Bergamaschi, I., P.V. Moore, and A.B. Tickner (2017) South-South Cooperation Beyond the Myths: Rising Donors, New Aid Practices? Springer, London.

Brauman, R. (2012) 'Médecins Sans Frontières and the ICRC: matters of principle'. International Review of the Red Cross. 94(888). pp. 1523-1535.

Briggs, C.L. and C. Mantini-Briggs (2009) 'Confronting Health Disparities: Latin American Social Medicine in Venezuela'. American Journal of Public Health. 99(3). pp. 549-555.

Buhmann, C.B. (2005) 'The role of health professionals in preventing and mediating conflict'. Medicine, Conflict, and Survival. 21(4). pp. 299-311.

Bull, H. (1977) The Anarchical Society: A Study of Order in World Politics. Columbia University Press, New York.

Buşoi, C. (2010) 'Health systems and the influence of political ideologies'. Management in Health. 14(2). pp. 4-6. 
Bussmann, M. and G. Schneider. 2016. A porous humanitarian shield: The laws of war, the red cross, and the killing of civilians. The Review of International Organizations. 11(3). pp 337359.

Chan, L.H. (2010) 'WHO: the world's most powerful international organisation?', Journal of Epidemiology \& Community Health. 64. pp. 97-98.

Chan, L.H. (2011) China engages global health governance: responsible stakeholder or system-transformer? Springer, London.

Chan, L.H., L. Chen, and J. Xu (2010) 'China's engagement with global health diplomacy: was SARS a watershed?’ PLoS medicine. 7(4). p. e1000266.

Cooley, A. and J. Ron (2002) 'The NGO Scramble: Organizational Insecurity and the Political Economy of Transnational Action'. International Security. 27(1). pp. 5-39.

Cuny, F. (1983) Disasters and Development. Oxford University Press, Oxford.

Devereux, S. (1993) Theories of Famine. Harvester Wheatsheaf, London.

de Waal, A. (2005) Famine that Kills: Darfur, Sudan. Revised edition. Oxford University Press, Oxford.

Diamond, L. and J. McDonald (1993) Multi-Track Diplomacy: A Systems Approach to Peace. Institute for Multi-Track Diplomacy, Washington, D.C.

Dijkzeul, D. (2003) 'Healing Governance? Four Health NGOs in War-Torn Eastern Congo'. Journal of International Affairs. 57(1). pp. 183-199.

Drury, A.C. and Olson, R.S. (1998) 'Disasters and political unrest: an empirical investigation'. Journal of Contingencies and Crisis Management. 6(3). pp. 153-161.

Duchacek, I.D., D. Latouch, and G. Stevenson (eds). (1988) Perforated Sovereignties and International Relations: Trans-Sovereign Contacts of sub-national Governments. Greenwood Press, Westport, CT.

Duffield, M. (2001) 'Global Governance and the New Wars: The Merging of Development and Security'. Zed Books, London.

Enia, J. (2008) 'Peace in its Wake? The 2004 Tsunami and Internal Conflict in Indonesia and Sri Lanka.'. Journal of Public \& International Affairs. 19. pp. 7-27.

Feinsilver, J.M. (2008) 'Oil-for-Doctors: Cuban Medical Diplomacy Gets a Little Help From a Venezuelan Friend'. Nueva Sociedad. 216. pp. 105-122.

Feinsilver, J.M. (2010a) 'Cuban medical diplomacy: when the left has got it right'. Council on Hemispheric Affairs. 6(4). pp. 81-94. 
Feinsilver, J.M. (2010b) 'Fifty years of Cuba's medical diplomacy: from idealism to pragmatism'. Cuban studies. 41(1). pp. 85-104.

Feldbaum, H. and J. Michaud (2010) 'Health diplomacy and the enduring relevance of foreign policy interests.' PLoS medicine. 7(4). pp. e1000226.

Fidler, D.P. (2004) SARS, Governance and the Globalization of Disease. Springer, London.

Forrest, K. (1995) 'Toward Beijing: linking HIV / AIDS to other women's issues is imperative.' AIDSlink: Eastern, Central \& Southern Africa. 32. p. 6.

Forster, L. (2015) 'The Soft Power Currencies of US Navy Hospital Ship Missions', International Studies Perspectives. 16(4). pp. 367-387.

Furedi, F. (2007) The changing meaning of disaster. Area. 39(4). pp. 482-489.

Ghinai, I., C. Willott, I. Dadari, and H.J. Larson (2013) 'Listening to rumours: What the northern Nigeria polio vaccine boycott can tell us ten years on'. Global Public Health. 8(10). pp. 1138-1150.

Gostin, L.O. (2015) World Health Organization Reform: Lessons Learned from the Ebola Epidemic. The Hastings Centre Report. 45(2). Pp. 6-7.

Gostin, L.O., M.C. DeBartolo, and E.A. Friedman (2015) 'The International Health Regulations 10 years on: the governing framework for global health security'. The Lancet. Elsevier, 386(10009), pp. 2222-2226.

Hewitt, K. (ed.) (1983) Interpretations of calamity from the viewpoint of human ecology. Allen \& Unwin, London.

Hotez, P.J. (2001) 'Vaccines as instruments of foreign policy.' EMBO Reports. 2(10). pp. 862868.

Hotez, P.J. (2014) 'Vaccine Diplomacy: Historical Perspectives and Future Directions'. PLoS Neglected Tropical Diseases. 8(6). pp. e2808.

Hotez, P.J., A. Vyazovaya, N. Solovieva, T. Sunchalina, and Y. Markelov (2017) 'RussianUnited States vaccine science diplomacy: Preserving the legacy'. PLOS Neglected Tropical Diseases. 11(5). p. e0005320.

Huang, Y. (2004) 'The SARS epidemic and its aftermath in China: a political perspective', in Learning from SARS: Preparing for the Next Disease Outbreak. Workshop Summary (Knobler S., Mahmoud A., Lemon S., Mack A., Sivitz L., \& K Oberholtzer eds.). National Academies Press, Washington. pp. 116-36.

Huang, Y. (2017) 'China's Response to the 2014 Ebola Outbreak in West Africa'. Global Challenges. 1(2). Paper 1600001. 
Hui, D. and M.K. Ng (2007) 'Politics and the management of public health disasters: Reflections on the SARS epidemic in greater China'. Asia-Pacific Journal of Public Health. 19(1_suppl). pp. 7-12.

Huish, R. and J.M. Kirk (2007) 'Cuban Medical Internationalism and the Development of the Latin American School of Medicine'. Latin American Perspectives. 34(6). pp. 77-92.

Jegede, A.S. (2007) 'What Led to the Nigerian Boycott of the Polio Vaccination Campaign?'. PLoS Medicine. 4(3). p. e73.

Katz, R., Kornblet, S., Arnold, G., Lief, E. and Fischer, J.E. (2011) 'Defining health diplomacy: changing demands in the era of globalization.' The Milbank quarterly. 89(3). pp. 503-523.

Kaufmann, J.R. and Feldbaum, H. (2009) 'Diplomacy And The Polio Immunization Boycott In Northern Nigeria’. Health Affairs. 28(4). pp. 1091-1101.

Keating, T.F. and W.A. Knight (2006) Building sustainable peace. United Nations University Press, Tokyo.

Kelman, I. (2007) ‘Hurricane Katrina disaster diplomacy’. Disasters. 31(3). pp. 288-309.

Kelman, I. (2012) Disaster Diplomacy-How Disasters Affect Peace and Conflict. Routledge, New York.

Kelman, I. (2016) 'Catastrophe and Conflict: Disaster Diplomacy and Its Foreign Policy Implications'. Brill Research Perspectives in Diplomacy and Foreign Policy. 1(1). pp. 1-76.

Kew, D. (2016) 'Civil Society, Conflict Resolution, and Democracy in Nigeria'. Syracuse University Press, Syracuse.

Koukis, T., I. Kelman, and N.E. Ganapati (2016) 'Greece-Turkey disaster diplomacy from disaster risk reduction'. International Journal of Disaster Risk Reduction. 17. pp. 24-32.

Krähenbühl, P. (2004) 'The ICRC's approach to contemporary security challenges: A future for independent and neutral humanitarian action'. International Review of the Red Cross, 86(855). pp. 505-514.

La Rosa, A.M. (2006) Humanitarian organizations and international criminal tribunals, or trying to square the circle. International Review of the Red Cross. 88(861). pp. 169-186.

Lee, J.W. and W.J. McKibbin (2004) 'Globalization and disease: The case of SARS'. Asian Economic Papers. 3(1). pp. 113-131.

Lewis, J. (1999) Development in Disaster-Prone Places: Studies in Vulnerability. IT Publications (Practical Action), Bradford.

Lischer, S.K. (2003) 'Collateral Damage: Humanitarian Assistance as a Cause of Conflict'. Foreign Affairs. 81(2). p. 177. 
Liu, P., Y. Guo, X. Qian, S. Tang, Z. Li, and L. Chen (2014) 'China's distinctive engagement in global health'. The Lancet, 384(9945). pp. 793-804.

Lu, R., J. Mackay, S. Niu, and R. Peto (2012) Tobacco: The Growing Epidemic: Proceedings of the Tenth World Conference on Tobacco or Health, 24-28 August 1997, Beijing, China. Springer, London.

Maini, R., L. Clarke, K. Blanchard, and V. Murray (2017) 'The Sendai Framework for Disaster Risk Reduction and Its Indicators-Where Does Health Fit in?'. International Journal of Disaster Risk Science, 8(2), pp. 150-155. doi: 10.1007/s13753-017-0120-2.

Manyanga, T., H. El-Sayed, D. Teye Doku, and J.R. Randall (2014) 'The prevalence of underweight, overweight, obesity and associated risk factors among school-going adolescents in seven African countries'. BMC Public Health, 14, article 887 https://bmcpublichealth.biomedcentral.com/articles/10.1186/1471-2458-14-887

Marmot, M. (2005) 'Social determinants of health inequalities.' The Lancet. 365(9464). pp. 1099-1104.

Murray, C., S. Kulkarni, C. Michaud, and N. Tomijima (2006) 'Eight Americas: investigating mortality disparities across races, counties, and race-counties in the United States'. PLoS, 3(9). pp. e260.

Navarro, V., C. Muntaner, C. Borrell, J. Benach, Á. Quiroga, M. Rodríguez-Sanz, N. Vergés, and M.I. Pasarín (2006) 'Politics and health outcomes'. The Lancet. 368(9540). pp. 1033-1037.

Nicolson, H.G. (1939) Diplomacy. Harcourt Brace, New York.

Okumu, W. (2003) 'Humanitarian International NGOs and African Conflicts'. International Peacekeeping. 10(1). pp. 120-137.

Oliver, T.R. (2006) 'The Politics of Public Health Policy'. Annual Review of Public Health. 27(1). pp. 195-233.

Olson, R.S. and A.C. Drury (1997) 'Un-therapeutic communities: a cross-national analysis of post-disaster political unrest'. International Journal of Mass Emergencies and Disasters, 15(2). pp. 221-238.

Olson, R.S. and V.T. Gawronski (2010) 'From disaster event to political crisis: a "5C+A" framework for analysis. International Studies Perspectives. 11: 205-221.

Pearson, J. (2004). Medical Diplomacy and the American Indian: Thomas Jefferson, the Lewis and Clark Expedition, and the Subsequent Effects on American Indian Health and Public Policy. Wicazo Sa Review. 19(1). pp. 105-130.

Pérez, L. (2014) Cuba: Between reform and revolution. Oxford University Press, Oxford.

Pottier, J. (2006) 'Roadblock Ethnography: Negotiating Humanitarian Access in Ituri, Eastern Dr Congo, 1999-2004’. Africa. 76(2). pp. 151-179. 
Quarantelli, E. (ed). (1998) What is a disaster? Routledge, London.

Scribner, S. (2017) On The Brink: As famine looms, world leaders must pay up and deliver political solutions to save lives. Oxfam, Oxford.

Shawcross, W. (2000) Deliver us from Evil: Warlords and Peacekeepers in a World of Endless Conflict. Bloomsbury, London.

Siddiqi, A. (2014) 'Climatic disasters and radical politics in southern Pakistan: the non-linear connection’. Geopolitics. 19(4). pp. 885-910.

Skinner, H., Z. Abdeen, H. Abdeen, P. Aber, M. Al-Masri, J. Attias, K.B. Avraham, R. Carmi, C. Chalin, Z. El Nasser, M. Hijazi, R.O. Jebara, M. Kanaan, H. Pratt, F. Raad, Y. Roth, A.P. Williams, A. and Noyek (2005) 'Promoting Arab and Israeli cooperation: peacebuilding through health initiatives'. Lancet, 365(9466). pp. 1274-1277.

Steinbruner, J.D. (1997) 'Biological Weapons: A Plague upon All Houses'. Foreign Policy. 109. p. 85.

Stoffels, R.A. (2004) 'Legal regulation of humanitarian assistance in armed conflict: Achievements and gaps'. International Review of the Red Cross. 86(855). pp. 515-546.

Swanson, W. (2012) 'Birth of a Cold War Vaccine'. Scientific American. 306(4). pp. 66-69.

Terry, F. (2002) Condemned to repeat? The paradox of humanitarian action. Cornell University Press, Ithaca.

Thompson, D. (2005) 'China's soft power in Africa: From the "Beijing Consensus" to health diplomacy'. The Jamestown Foundation China Brief. 5(21). https://jamestown.org/program/chinas-soft-power-in-africa-from-the-beijing-consensus-tohealth-diplomacy

UNISDR (2017) Terminology. UNISDR (United Nations International Strategy for Disaster Reduction), Geneva.

Waller, S.G., J.B. Ward, and M.A. Montalvo (2017) 'Cuba's 50-Year Health Diplomacy Program: Lessons Learned for Global Health Engagement.' Military medicine. 182(1). pp. 1451-1452.

Wang, Y. (2013) 'The H7N9 Influenza Virus in China - Changes since SARS', New England Journal of Medicine. 368(25). pp. 2348-2349.

Wang, Z., C. Li, Z. Yang, J. Ma, and Z. Zou (2017) 'Fetal and infant exposure to severe Chinese famine increases the risk of adult dyslipidemia: Results from the China health and retirement longitudinal study'. BMC Public Health. 17(1). p. 488.

WHO (2003) 'Summary of probable SARS cases with onset of illness from 1 November 2002 to 31 July 2003'. WHO (World Health Organization), Geneva. 
WHO (2010) 'A Conceptual Framework for Action on the Social Determinants of Health: Social Determinants of Health Discussion Paper 2'. WHO (World Health Organization), Geneva.

WHO (2013) 'Rapid risk assessment of acute public health events'. WHO (World Health Organization), Geneva.

WHO (2015) 'WHO | Update 95 - SARS: Chronology of a serial killer'. WHO (World Health Organization), Geneva.

WHO (2017a) '10 facts on polio eradication'. WHO (World Health Organization), Geneva.

WHO (2017b) 'Circulating vaccine-derived poliovirus type 2 - Syrian Arab Republic'. WHO (World Health Organization), Geneva.

Wisner, B., P. Blaikie, T. Cannon, and I. Davis (2004) At Risk: Natural Hazards, People's Vulnerability and Disasters. Routledge, London.

Yánez, H. (2005) "The Cuba-Venezuela Alliance: "Emancipatory Neo-Bolivarismo" Or Totalitarian Expansion?' Institute for Cuban and Cuban-American Studies Occasional Papers. 7. 